\title{
Famílias: Entre Dispositivos Jurídicos, Rizomas, Identidades e Filiação
}

Familias: Entre Dispositivos Jurídicos, Rizomas, Identidades y Filiación

Families: Between Legal Devices, Rhizomes, Identities and Filiation

Jimena de Garay Hernández

ORCID: https://orcid.org/0000-0002-0564-1056 Universidade do Estado do Rio de Janeiro, Rio de Janeiro/Brasil

Roberta Gomes Nunes

ORCID: https://orcid.org/0000-0003-1545-6169 Tribunal de Justiça do Estado do Rio de Janeiro, Rio de Janeiro/Brasil

Flávio Lopes Guilhon

ORCID: https://orcid.org/0000-0002-8407-1353

Declaração de Direito Autoral

A submissão de originais para este periódico implica na transferência, pelos autores, dos direitos de publicação impressa e digital. Os direitos autorais para os artigos publicados são do autor, com direitos do periódico sobre a primeira publicação. Os autores somente poderão utilizar os mesmos resultados em outras publicações indicando claramente este periódico como o meio da publicação original. Em virtude de sermos um periódico de acesso aberto, permite-se o uso gratuito dos artigos em aplicações educacionais e científicas desde que citada a fonte conforme a licença CC-BY da Creative Commons.

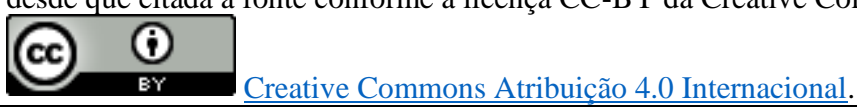

\section{Resumo}

No presente artigo usaremos como disparador da análise um caso ao qual tivemos acesso em experiências de pesquisa. A partir dele, analisaremos as forças que se atravessam na produção e transformação das relações familiares, considerando os aspectos cotidianos e jurídicos, com ênfase nos múltiplos discursos, sobretudo os pautados no machismo, sexismo, heterossexismo e LGBTfobia, que delimitam a pluralidade das existências no campo da diversidade sexual e de gênero, bem como as potencialidades rizomáticas de ser família. Essas forças extremamente complexas se entrelaçam na contemporaneidade, apesar dos muitos avanços neste campo, na tentativa de afirmar apenas um modelo único de ser, de se relacionar e de ser família, a partir de uma matriz cisheteronormativa que tende a excluir outros modos de vida.

Palavras-chaves: Famílias; Diversidade sexual e de gênero; Rizoma; Heteronormatividade; Sistema de justiça.

\section{Resumen}

En el presente artículo usaremos como disparador del análisis un caso al cual tuvimos acceso en experiencias de investigación. A partir de este, vamos a analizar las fuerzas que se atraviesan en la producción y transformación de las relaciones familiares, considerando los aspectos cotidianos y jurídicos, con énfasis en los múltiples discursos, sobre todo los pautados en el machismo, sexismo, heterosexismo y LGBTfobia, que delimitan la pluralidad de las existencias en el campo de la diversidad sexual y de género, así como las potencialidades rizomáticas de ser familia. Esas fuerzas extremadamente complejas se entrelazan en la contemporaneidad, a pesar de todos los avances en este 
campo, intentando afirmar apenas un modelo único de ser, de relacionarse y de ser familia, a partir de una matriz cisheteronormativa que tiende a excluir otros modos de vida.

Palabras clave: Familias; Diversidad sexual y de género; Rizoma; Cisheteronormatividad; Sistema de justicia.

\begin{abstract}
In this article, we will use as a trigger for the analysis a case that we had access to in research experiences. From it, we will analyze the forces that are involved in the production and transformation of family relationships, considering the everyday and legal aspects, which delimit the plurality of existences in the field of sexual and gender diversity, as well as the rhizomatic potentialities of being a family. With emphasis on multiple discourses, especially those based on sexism, heterosexism and LGBTphobia, plurality of existences in the field of sexual and gender diversity, as well as the rhizomatic potentialities of being a family. These extremely complex forces intertwine in the contemporary world, despite the many advances in this field, in the attempt to affirm only a unique model of being, of relating and of being family, from a cisheteronormative matrix that tends to exclude other ways of life.
\end{abstract}

Keywords: Families; Sexual and gender diversity; Rhizome; Cisheteronormativity; Justice system.

\section{Introdução}

A proximidade afetiva e o engajamento para com uma Psicologia comprometida socialmente com a sociedade e as transformações que lhe são peculiares a partir do paradigma ético-estético-político (Rolnik, 1993), é o que aproxima as autoras e possibilita esta produção cartográfica-textual. Partimos, então, de pesquisas e intervenções realizadas com famílias, a partir das discussões sobre diversidade sexual e de gênero, em processos de mestrado e doutoramento. Através destas experiências profissionais e de militância, fomos problematizando, a partir dos desafios éticos e políticos pelos quais fomos atravessadas, os efeitos produzidos quando do encontro de nossas práticas com as discussões relativas à diversidade sexual e de gênero (com ênfase nas trajetórias de transição de gênero, retificação de nome e gênero no registro civil), homo/transparentalidade (parentalidade que se constitui a partir de experiências não fundamentadas na cisheterosexualidade), violência intrafamiliar e cisheteropatriarcal (como os estupros coletivos e corretivos e cárcere privado) direito familiar (como as regulamentações de visitas, guarda e pensão alimentícia), direito ao nome e ao exercício das funções paterna e materna. Para citar algumas.
Inicialmente, faz-se necessário comunicar o que aqui estamos entendendo por família, gênero e sexualidade, principais dispositivos do relato. Ao considerar as transformações ocorridas na sexualidade do final do século XVIII ao final do século XIX, da valorização do corpo e de uma sexualidade preciosa para uma sexualidade recoberta, Foucault considera a importância assumida pelo sexo como foco da disputa política, através das disciplinas do corpo e do sexo, como pertencente à regulação das populações (Foucault, 1988). Além de propor que este corpo foi o primeiro objeto forjado pelo capitalismo, no qual se localiza a força de produção e a força de trabalho (Foucault, 1979). Neste contexto, o autor segue afirmando "O corpo é uma realidade bio-política", onde o controle sobre os indivíduos começa no corpo e não opera simplesmente na consciência ou ideologia, evidenciando que foi no corpo que a sociedade capitalista investiu (Foucault 1979, p. 80).

Em sua revisão bibliográfica acerca da discussão de gênero, Jimena de Garay Hernández sinaliza que "construção do gênero não é fixa nem determinada por corpos sexualmente diferenciados, pois esses corpos também são construções que se fazem a partir 
de certos discursos binários" (de Garay Hernández, 2013, pp.17-18). A autora afirma a importância de olharmos gênero e sexo como devires que se encontram em constante diálogo e transmutação, transpassando os limites da legibilidade que se manifestam no campo das performatividades.

Segundo Donna Haraway, nos sentidos crítico e político, "o conceito de gênero foi articulado e progressivamente contestado e teorizado no contexto dos movimentos de mulheres feministas do pós-guerra" (Haraway, 2004, p. 211). De acordo com a autora, gênero se constitui enquanto um conceito feminista que contesta a naturalização da diferença sexual, materializada em múltiplas arenas de luta. Nesse sentido, a teoria e prática feministas se debruçam na produção de transformações nos sistemas históricos que marcam a diferença sexual, "nos quais 'homens' e 'mulheres' são socialmente constituídos e posicionados em relações de hierarquia e antagonismo" (Haraway, 2004, p. 211). Hoje essas transformações são perceptíveis, o que reverbera em vivências de corpos, sexualidades e gênero. Louro (2013) sinaliza que sem dúvida, todas essas transformações afetam o modo como se vive e como se constitui as identidades de gênero e sexuais: "na verdade, tais transformações constituem novas formas de existência para todos, mesmo para aqueles que, aparentemente, não as experimentam de modo direto" (Louro, 2013, p.10).

No que diz respeito às noções de família, no início de seu livro Novas famílias: conjugalidade homossexual no Brasil contemporâneo, Luiz Mello afirma que "o modelo de família moderna, hegemônico no mundo ocidental, é entendido [...] como uma construção econômica, política, social e cultural, demarcada temporal e espacialmente" (Mello, 2005, p.25). Tal afirmativa nos auxilia a pensar sobre as transformações na instituição família, bem como os desafios que vão se apresentando a ela, no que tange à nomeação filial, relações conjugais e parentais, construção de cuidados e afetividades.
Por sua vez, Fonseca (2009) menciona dois princípios a partir dos quais a noção de família se constrói como algo natural: o primeiro tem relação com o componente biológico e, nesse sentido, a noção de família decorre da natureza. Assim, a biologia seria suficiente para garantir os vínculos familiares, supondo a universalidade desse modelo familiar. Nesta perspectiva, a metáfora do sangue transparece intimidade, proximidade, garante o pertencimento e matiza o vínculo emocional. O segundo princípio, de acordo com a autora, se relaciona com o desejo. A partir da revolução industrial, o amor emerge como fator fundamental na vida familiar, e os filhos e as filhas, que antes significavam a perpetuação da família, da empresa familiar, agora adquirem forte valor afetivo. A ênfase atual nas relações afetivas e, consequentemente a valorização dos vínculos socioafetivos, ampliaram as possibilidades de organização familiar, legitimando minimamente famílias antes impensáveis ou vividas de forma marginalizada - ainda que essa abertura não seja vivida independentemente das desigualdades sociais (Fonseca, 2009). Das famílias monoparentais, aos casais de responsáveis com o mesmo sexo, da vivência da homosexualidade às novas vivências no campo da identidade de gênero, dimensões da vida que podem coexistir.

\section{Conforme Corrêa (2012), as} tradicionais apresentações das relações familiares nem sempre dão conta da sua complexidade, já que existem relações não pertencentes ao que podemos chamar de regimes de visibilidade e de enunciabilidade nas configurações genealógicas. Ainda segundo Corrêa, a genealogia "esfumaça o tempo, como se todos os 'parentes' fossem copresentes na sua representação" (Corrêa, 2012, p.200). Nesse sentido, podemos pensar o "modelo genealógico", como aquele

segundo o qual cada indivíduo é saído de dois outros indivíduos de uma geração ascendente e de sexo diferente que $o$ teriam em princípio conjuntamente engendrado, seu pai e sua mãe. Este modelo não veicula 
apenas a ideia que a filiação é um fato natural. Ele é acompanhado sobretudo de uma norma, aquela da exclusividade da filiação, isto é que cada indivíduo não é colocado em posição de filho ou filha senão em relação a um único homem e a uma única mulher. Isto explica as contradições nas quais se batem nossas sociedades quando coexistem vários pais para uma mesma criança. Que fazer dos pais "a mais"? (Ouellette, citado por Fine, 2001, p. 42, tradução nossa)

Destarte, podemos pensar a árvore genealógica enquanto um sistema arborescente, ou seja, um sistema hierárquico que comporta "centros de significância e de subjetivação" (Deleuze \& Guattari, 1995, p.26). Diferente de uma árvore, no sistema rizomático não há unidade, mas multiplicidade, não existem pontos, senão linhas, não há começo nem fim, mas um meio pelo qual cresce e transborda, não é objeto de reprodução, mas procede por variação, expansão. Dessa forma, é possível apresentar as famílias como mapa que "é aberto, é conectável em todas suas dimensões, desmontável, reversível, suscetível de receber modificações constantemente. Ele pode ser rasgado, revertido, adaptar-se a montagens de qualquer natureza" (Deleuze \& Guattari, 1995, p.22).

Podemos pensar, assim, mais do que em árvores, em rizomas genealógicos, "onde as relações são variáveis e os diagramas de parentescos se apresentam como processuais e as categorias como plásticas" (de Garay Hernández, 2013, p.137). Como apontado por de Garay Hernández (2013, p. 138), "podemos desvincular a ideia de cuidado das crianças da autoridade e hierarquia entre as gerações, entre gêneros, relações mutáveis, gêneros mutáveis, parentalidades mutáveis, e assim fazer um mapa da família como composição de afetos e não como um modelo fixo de relações rígidas". A autora segue afirmando sobre a importância de considerar que os modelos de rizoma e árvore não se opõem ou se excluem, visto que um rizoma pode ser considerado enquanto "estratos que se enraízem, linhas de fuga que se cristalizem, formas que se decalquem, territorialidades se endureçam (de Garay Hernández, 2013, p.138).

Apesar de o modelo de família brasileira alicerçar-se sobre elementos cristãos e burgueses, os desdobramentos políticos da diversidade das famílias e seus arranjos já começam a se fazer presentes e visíveis em diferentes níveis, enunciando sua pluralidade ao lado da configuração familiar considerada como única até então. Além de conseguirmos, mesmo que a passos lentos, colocar em análise a instituição familiar e pensá-la não mais como um espaço fixo, natural e idealizado, mas enquanto um possível espaço dramático de violências, disputas e conflitos, por conta das desigualdades e estruturas hierárquicas, a partir do sexo, da geração, da raça e da sexualidade (Saffioti, 2004).

Nesse sentido, é fundamental considerar as inflexões que têm produzido uma desnaturalização de um modelo estanque de família. Se, por um lado, tem se contestado a ideia de que a família no modelo nuclear, burguês, cisheteronormativo e branco pode muitas vezes esconder profundas violências com o intuito de preservar sua hierarquia sociopolítica na sociedade, por outro, a visibilidade da pluralidade de famílias tem possibilitado pensar que existem, sempre existiram e podem existir famílias muito diversas, nas quais as pessoas podem se desenvolver plenamente. Isso, certamente, não as isenta de vivenciar processos violentos. Da mesma forma, podemos dizer que o fato de uma família se configurar de forma semelhante ao modelo hegemônico não faz com que ela não esteja aberta a produções rizomáticas de afirmação de vida.

\section{Métodos}

A partir das discussões apresentadas acima, parece interessante nos debruçarmos sobre a possibilidade de colocar em análise nossas práticas profissionais a partir de como elas se afetam/são afetadas pelas interlocuções entre famílias, Justiça e Psicologia. Assim, 
tentaremos provocar, através da discussão de um caso ao qual tivemos acesso nas nossas pesquisas, a realização de torções, dobraduras, rupturas e (re)construções teóricometodológicas, de modo a propor a construção de intervenções inventivas (Kastrup, 2012) junto às subjetividades que experienciam acontecimentos como os dos e das personagens acompanhadas neste caso-disparador.

$\mathrm{O}$ caso aqui discutido conecta as autoras, na tentativa de analisar acerca do que ele articula e assim pensar os desafios que se apresentam à Psicologia na contemporaneidade, sobretudo, no que se refere às especificidades que têm atravessado o cotidiano das muitas famílias brasileiras. Famílias cuja composição e relações nos lembram muito mais um rizoma do que a organizações arbóreas. A seguir o nosso casodisparador, no qual usamos nomes fictícios:

M. quando tinha 15 anos iniciou seu primeiro relacionamento homossexual com uma jovem da mesma idade. O pai de sua namorada, ao perceber o envolvimento de ambas, estuprou M. na frente de sua filha como forma de "ensiná-las" a serem mulheres e gostarem de homens. M. engravidou como consequência do estupro e teve a criança, da qual foi a única responsável nos primeiros anos de vida da filha. Alguns anos depois conheceu Yan e com ele manteve um relacionamento amoroso, advindo sua segunda filha. O mesmo assumiu a paternidade da primeira criança, passando a ser o pai registral e afetivo de ambas. O relacionamento se findou, mas a amizade permaneceu. Na vida adulta, com duas filhas, M. se reconheceu como lésbica e manteve um relacionamento duradouro com Verônica, que não tinha filhos. Algum tempo depois, M. começou a transição corporal para o gênero masculino, identificando-se como homem trans. Iniciou tratamento hormonal e realizou mastectomia, passando a se reconhecer como Mário. Planejou junto com Verônica a vinda de um filho e, com a doação de sêmen de Yan, realizaram uma inseminação caseira, com Verônica como gestante. Júlio nasceu e foi recebido com muito afeto e alegria por todas/os. Mário não registrou o filho que teve com Verônica como seu, pois esperava realizar a retificação de nome antes de realizar esse movimento, tendo o menino apenas o nome de Verônica no registro de nascimento. Mário também teve grandes dificuldades em encontrar emprego devido à transfobia do mercado de trabalho. Quando Júlio tinha cinco anos de idade, Mário e Verônica se separaram. No início ambos acordaram sobre a visitação e os alimentos do filho, porém quando Verônica iniciou novo relacionamento com outro homem trans, Mário passou a ter dificuldades de acesso à criança. Verônica começou a alegar que Mário era violento e agressivo quando contrariado e que expunha Júlio a situações de risco. Mário, diante do impedimento de acessar o filho, busca a Justiça, na tentativa de ter seu direito de pai reconhecido. Seu processo de retificação de nome e gênero ainda estava em andamento na Justiça, materializando o desejo por ser reconhecido juridicamente como homem e pai da criança, tendo assim garantido o exercício da paternidade. Mário encontra-se em novo relacionamento amoroso, sem que os familiares de sua atual companheira saibam do fato de ter transicionado.

\section{Resultados e discussão}

Partindo deste caso-disparador, podemos colocar em evidência diversos fios de tensão que sinalizam, por um lado, a necessidade da regulação e proteção judicial, a partir das configurações legais no campo dos direitos da família, infância e adolescência, transição do corpo ao gênero e retificação de nome no registo civil. Por outro, as tensões implicadas na judicialização da vida, que muitas vezes produz durezas e cerceia a capacidade de produção de formas de ser e se relacionar de maneira livre e autônoma.

Como apontado anteriormente, é possível identificar um leque de situações de violação de direitos de pessoas LGBT por parte de familiares, que são cotidianamente observadas nos serviços onde atuamos e nas pesquisas que desenvolvemos, o nosso caso apresenta uma terrível e não pouco frequente violência em e "em nome" da família, homens, quase sempre familiares ou conhecidos, 
estupram lésbicas e homens trans, com o objetivo de "corrigir" supostas desviações morais e reenquadrá-las no modelo cis-héteronormativo. Por exemplo, no contexto do projeto "Transexualidades e saúde pública no Brasil: entre a invisibilidade e a demanda por políticas públicas para homens trans" (NUHUFMG, 2015), 30,77\% dos entrevistados declararam ter sido forçados a realizar práticas sexuais que não desejariam ter feito, $15,38 \%$ declararam ter sofrido sexo forçado/estupro e $11,54 \%$ declararam ter sofrido tentativa de sexo forçado/estupro. Por sua vez, o "Dossiê sobre lesbocídio no Brasil" (Peres, Soares, \& Dias, 2018) relata casos de estupro seguido de morte. Ainda segundo esse dossiê, não é raro que homens que possuem algum grau de parentesco com lésbicas executem assassinato delas ou das companheiras, pois

estes homens partem de uma premissa fundamentada no patriarcado que delega aos homens o direito sobre as mulheres da família, como extensão do seu poder, e sentem-se no direito de gerir a vida e a morte delas de acordo com seus próprios valores. Nos casos em que quem é assassinada é a cônjuge, ou seja, alguém que não possui vínculo consanguíneo com o assassino percebe-se que há uma tentativa de zelar pela imagem pública da unidade familiar por meio do extermínio do elemento estranho que macula a imagem da família heterossexual tradicional. Em todas as circunstâncias, o que é recorrente é o fato de um ou mais homens de uma família considerarem-se com o direito e o dever de decidir o destino das mulheres, agindo contra a vida delas em nome da conservação de uma estrutura heterossexual (Peres et al., 2018, p. 29).

\footnotetext{
${ }^{1}$ O Código Penal de 1940, no seu artigo 128 inciso II, aponta que "Não se pune o aborto praticado por médico se a gravidez resulta de estupro e o aborto é precedido de consentimento da gestante ou, quando incapaz, de seu representante legal".
}

Em alguns casos, como o do Mário, os "estupros corretivos" têm como um dos seus desdobramentos gravidezes indesejadas. Embora contraditório na perspectiva dos Direitos Humanos, o argumento parece fazer sentido para os perpetuadores de tais violências: é mais aceitável violentar sexualmente uma jovem, do que aceitar uma sexualidade ou identidade de gênero não hegemônica, sobretudo quando estas violências tem como objetivo readequar corpos num certo funcionamento. Dessa forma, a família opera como sustentadora da matriz moral, na qual a lesbianidade ou a transexualidade são mais reprováveis do que o estupro, inclusive de uma criança ou adolescente. $\mathrm{O}$ quadro é ainda mais violento no momento em que, apesar de que o estupro seja condição legal para a interrupção de uma gravidez, o contexto brasileiro apresenta inúmeros obstáculos para que isso aconteça, tanto nos serviços de saúde, quanto no discurso da opinião pública, que criminalizam o aborto até nos casos em que há garantia legal ${ }^{1}$.

Porém, no panorama apresentado neste caso, os arranjos familiares chamam muito a atenção, surpreendendo na multiplicidade de vínculos que podem existir de forma simultânea, mas também independente. Os eixos jurídico, biológico e afetivo, segundo Brito e Ayres (2004), se conjugam na constituição da parentalidade e as autoras chamam a atenção para as análises contraditórias que valorizam um eixo, geralmente o biológico (sanguíneo) em detrimento do outro, em determinadas situações. Apontam ainda que, na atualidade, esses eixos podem ser exercidos por pessoas distintas em situações nas quais mais de um homem e/ou mulher podem ser pais e mães de uma mesma criança. De acordo com Costa, tanto as análises da teoria duogenética quanto o que se refere ao 'modo de reprodução natural' sinalizam para a existência de uma atribuição 
de valor cultural ao natural/biológico, mesmo podendo este lógica ser passível de interferências sociais/humanas, conforme observa-se nas tensões existentes na adoção e uso de tecnologidas reprodutivas (Costa, 2002, p. 354).

Cláudia Fonseca afirma que "a homoparentalidade, assim como outras formas familiares consideradas contemporâneas ${ }^{2}$, são vistas como "co-produções" que envolvem além de valores culturais - lei, tecnologia e dinheiro" (Fonseca, 2008, p.769). Fazendo relação com o caso-disparador, é possível perceber que apesar da não existência da filiação jurídica, Mário luta por seus direitos de pai, afirmando sua participação no planejamento e concepção do filho, assim como na existência do mesmo, nutrindo afeto e desejo por exercer e garantir o exercício da paternidade. Tomando a questão das "coproduções" apontada por Fonseca, podemos também sinalizar os mecanismos que vão sendo construídos, no caso da inseminação artificial caseira, para se efetivar desejos que inicialmente apenas seriam alcançados com elevado recurso financeiro, ou seja, por parte de uma pequena parcela da população.

A intercalação de parâmetros na definição de vínculo parental/familiar faz oscilar os critérios que demarcam o reconhecimento do vínculo familiar, de acordo com a interpretação de quem julga e com os interesses envolvidos, o que pode sugerir que a simultaneidade dos critérios talvez seja mais propícia para pensar a diversidade dos múltiplos contextos familiares. O equívoco parece estar relacionado com a exigência de se escolher ou ordenar em quais padrões se quer balizar as definições de filiação, como se o foco

\footnotetext{
2 Importante pensar que, embora a visibilidade e reconhecimento social e jurídico de famílias que não fazem parte do modelo de família seja relativamente recente, elas têm historicamente encontrado os meios de existir e subsistir (de Garay Hernández, 2013).

${ }^{3}$ Família tamanho família. Eu, minhas mães e meu pai: em decisão inédita, justiça gaúcha autoriza registro de nascimento com três responsáveis e seis avós. In: $\mathbf{O}$ Globo.caderno sociedade, p. 38, 13 set 2014, reportagem de Ilha, F. \& Grandelle, R.
}

fosse a busca de uma certa verdade, e não o bem-estar das pessoas integrantes da família.

No caso-disparador temos Mário lutando pelo reconhecimento da paternidade de Júlio, Verônica desejando assumir os cuidados do filho com seu atual companheiro e alegando que Mário não tem condições de conviver com a criança, enquanto ele luta por conseguir exercer seu lugar de pai. A discussão em relação ao sangue, sêmen e afeto vem à tona trazendo questionamentos a respeito do que seria necessário para que os vínculos familiares fossem definidos e garantidos.

$\mathrm{Na}$ atualidade, jurisprudências têm ampliado $\mathrm{o}$ entendimento de família $\mathrm{e}$ transformado os regimes de visibilidade e enunciabilidade sobre as suas conjugações. Em decisão judicial de setembro de 2014, na região Sul do Brasil, um juiz foi favorável ao registro de duas mães, um pai e seis avós de uma mesma criança. O magistrado denominou "ninho multicomposto"3, privilegiando a proteção e o afeto da criança e reconhecendo a pluriparentalidade. Nunes, Pereira \& Uziel (2014) analisam que neste caso "houve a conjugação do viés biológico e o socioafetivo, entendidos como dimensões distintas e igualmente legítimas na constituição do vínculo de filiação, num modelo mais aditivo que substitutivo das referências parentais"4.

No entanto, quando o caso envolve pessoas trans, a cisnorma faz com que questão não seja tão simples. Isso porque existe a presunção de que duas pessoas do mesmo gênero não teriam gerado uma criança, porém essa hipótese é apenas verdade quando ambas são cisgênero, ou seja, quando se identificam com o gênero designado ao nascimento. Nenhuma das determinações recentes do STF e

\footnotetext{
${ }^{4}$ Nunes, R. G., Pereira, C.S., \& Uziel, A. P. (2014). Família: as amarras do sangue. Trabalho apresentado na: I Bienal Latinoamericana de Infancias y Juventudes: democracias, derechos humanos y ciudadanías. Centro de Estudios Avanzados en Niñez y Juventud - CINDE. Universidad de Manizales.
} 
do CNJ prevê como lidar com casos em que haja duas mães ou dois pais biológicos ${ }^{5}$. Desde março de 2018, pessoas transexuais maiores de 18 anos podem requerer a alteração de seu prenome em qualquer cartório no Brasil, segundo determinação do Supremo Tribunal Federal (STF), que foi regulamentada pelo Conselho Nacional de Justiça (CNJ) em junho do ano passado. De acordo com o Provimento No 73 de 28/06/2018 do CNJ, a alteração independe de autorização judicial prévia, comprovação de cirurgia ou de tratamento hormonal, dependendo apenas da livre manifestação de vontade da pessoa. No entanto, é importante destacar que nem todos os cartórios realizam o processo sem impor obstáculos às pessoas que o solicitam ${ }^{6}$, o que perpetua as dificuldades que as pessoas trans enfrentam para construir uma vida em uma sociedade na qual esses documentos são imprescindíveis, incluindo o mercado de trabalho, como no caso de Mário.

Para Vianna (2006), as decisões dos avaliadores (operadores do campo jurídico ou da assistência social) com pouca frequência traduzem a realidade, não esgotam, tampouco obedecem ao previsto nas normas, tendo em última análise balizadores morais determinantes, a partir dos quais diversas possibilidades podem ser inventadas. Neste sentido são raras as composições entre vínculos, afetos, reconhecimento jurídico, etc. Moraes (2014) destaca a formação ideológica dos operadores de justiça, especialmente dos magistrados que têm a palavra final como um dos atravessamentos nos julgamentos, o que pode interferir diretamente em suas decisões. Neste contexto, é válido destacar a importância do papel do/a psicólogo/a no campo jurídico como aquele que pode auxiliar as pessoas a terem seus direitos garantidos e respeitados dentro de suas especificidades e diferenças, contribuindo para a eliminação da violência, discriminação e preconceito e para o

${ }^{5}$ https://www.sul21.com.br/ultimas-

noticias/geral/2018/08/mesmo-com-decisao-do-stfpessoas-trans-enfrentam-dificuldades-para-registrarseus-filhos/ reconhecimento da possibilidade de haver várias formas de existências no mundo.

Em estudo realizado por Pontes, FeresCarneiro e Magalhães (2017) com lésbicas, "verificou-se que nas constituições familiares estudadas, as crianças, de fato, identificam as duas mulheres como mães, quando ambas assim se assumem, demonstrando que o laço afetivo cumpriu o papel de vincular" (p.276). Por sua vez, em pesquisa com famílias de gays e lésbicas ao analisar as concepções de paternidade e de maternidade atualizadas nas configurações familiares coparentais realizadas por gays e lésbicas na França, Tarnovski, identificou tensões no que tange às modalidades de compartilhamento das crianças entre os parceiros, que produzem transformações e mobilizações nas definições acerca da maternidade e paternidade, confirmando assemetrias que persistem no campo da parentalidade, no entando, segue ainda o autor afirmando que estas definições não dizem respeito apenas ao reflexo de supostas 'imposições' de modelos e normas culturias e sociais, mas, se apresentam enquanto o "resultado de apropriações realizadas pelos atores para legitimar suas posições em uma situação marcada por constantes renegociações quanto aos contornos e ao conteúdo da família" (Tarnovski, 2013, p. 89).

Em relação à organização da família do caso aqui relatado, observamos que montar uma tradicional árvore genealógica torna-se um desafio. As relações estabelecidas são biológicas, sociais (de cuidados, dependência ou apoio financeiro, convivência) e jurídicas. Os níveis de reconhecimento são variados. As relações têm mudado ao longo dos anos, bem como os corpos e os nomes. No entanto, podemos pensar que a família aqui em questão não é unicamente rizomática, pois também se diagrama com algumas arborescências. Vemos violência, vemos conflitos cuja mediação é

${ }^{6}$ https://oglobo.globo.com/rio/bairros/burocracia-criabarreiras-para-alteracao-do-nome-de-registro-emcartorios-22636699 
delegada ao sistema de justiça, vemos durezas. As pessoas que procuram o sistema de justiça, geralmente o fazem por não terem conseguido resolver seus conflitos diretamente com a outra parte, delegando a um terceiro, o/a juiz/a, a decisão da lide. No entanto, nos casos atendidos no Judiciário nem sempre uma decisão judicial resolve o conflito e/ou garante os direitos de todos/as, sendo os/as envolvidos/as chamados/as a refletir e criar novas formas de lidar com as suas questões e especificidades. De Garay Hernández sinaliza que "o fato de as famílias se configurarem de formas mais rizomáticas, não significa que não existam nelas algumas noções de raiz e de tronco, estabelecendo-se hierarquias", neste contexto, segue afirmando acerca da necessidade e da "importância de religar os decalques ao mapa, abrir as linhas de fuga possíveis, explodir os estratos, romper as raízes e operar novas conexões $(2013$, p.138) .

Tal afirmativa dialoga diretamente com o entendimento de Foucault, quanto ao poder ser como um "feixe de relações mais ou menos organizado, mais ou menos piramidalizado, mais ou menos coordenado" (Foucault, 1979, p.248) que se exerce a partir de inúmeros pontos e em meio a relações desiguais e móveis, sem, no entanto encontrarem-se localizados em um ponto específico da estrutura social. Nesse sentido, a separação dos casais é uma preocupação de muitas pessoas LGBT no que diz respeito aos direitos que tanto adultos quanto crianças vão ter garantidos em uma possível ruptura (de Garay Hernández, 2013). Quiçá essa possibilidade seja uma motivação mais forte para formalizar as relações perante o Estado -através do casamento- do que uma idealização dessa formalização enquanto fornecedora de uma inteligibilidade social. A questão colocada é a necessidade de uma proteção judicializada tanto frente à LGBTfobia de familiares que possam querer interferir nos caminhos trilhados do casal e/ou da família, quanto de conflitos e inclusive violência entre o casal, onde o diálogo não seja mais possível.

Esse quadro é ainda mais complexo no nosso caso-disparador, no qual os entraves burocráticos impediram que Mário conseguisse retificar seu nome antes de se casar com Verônica e/ou de registrar Júlio como seu filho. No regime de inteligibilidade, antes de reivindicar que os filhos eram dele (uma filiação), Mário precisava reivindicar que ele era ele (um reconhecimento da sua identidade). Assim, a proteção que um meio jurídico poderia ter outorgado, não foi garantida justamente pelas barreiras que o sistema de justiça impõe por ser pautado pela imposição do modelo cisheteronormato e patriarcal. É importante também considerar que esse sistema, com suas linhas duras, não deixa de ser acionado por pessoas que são excluídas por ele ou o rejeitam, pois ele ainda se apresenta como uma forma de resolver disputas e violências. Neste cenário, no qual diferentes forças incidem, Azerêdo (2010) problematiza a questão da ética e das práticas no contexto da discussão sobre a diversidade sexual e de gênero, sobretudo, quando se trata de uma prática não psicologizante e normatizadora de vidas. Segundo a autora, estas discussões têm possibilitado a abertura para uma perspectiva crítica, na discussão de gênero e sexualidade, que ao articular e engajar diferentes projetos de mudança, colabora na luta contra o preconceito e a discriminação (Azerêdo, 2010, p. 186).

No que tange à discussão de gênero, a célebre frase "não se nasce mulher, mas tornase mulher", de Simone de Beauvoir, abre caminho para ampla reflexão, enfatizando o tornar-se e o vir-a-ser. Além de propiciar o início de um rompimento com as expectativas sociais de gênero que vêm, ao longo da história, aprisionando corpos e impossibilitando vivências que fogem ao binarismo mulherhomem, fêmea-macho e feminino-masculino. Afirmar-se mulher ou homem estaria, deste modo, associado a determinadas performatividades e repetição estilizada de determinados atos, de acordo Butler, a "performatividade deve ser compreendida não como um 'ato' singular ou deliberado, mas, em vez disso, como a prática reiterativa e citacional pela qual o discurso produz os efeitos que ele nomeia" (Butler, 2013, p. 154). Neste sentido, ao discutir a constituição do gênero através das 
performatividades, a autora sinaliza que "o gênero não é de modo algum uma identidade estável ou um local de acção, do qual provém vários actos; é antes uma identidade tenuemente constituída no tempo - uma identidade instituída através de uma repetição estilizada de actos" (Butler, 1998, p. 70, tradução nossa).

No nosso caso, Mário foi designado como Maria ao nascer, foi transformado em mãe pelo estupro, transicionou, se afirmou como Mário, virou pai; mas os marcadores sociais, pautados na moralidade e em uma concepção cis-hétero-normativa, invisibilizam vivências e seguem limitando, quando não exterminando, corpos que subvertem. Por exemplo, $85,7 \%$ dos homens trans entrevistados pelo projeto "Transexualidades e saúde pública no Brasil” (NUH-UFMG, 2015) já pensaram em suicídio ou tentaram cometer o ato, mostrando até que ponto as violências vivenciadas sufocam as pessoas cuja performatividade transgride a hegemonia.

Corpos como os do Mário, que fogem da matriz cisheternormativa, são, de uma ou outra forma, produzidos e acionados pelo Estado no controle das relações e na delimitação do regime de inteligibilidade. Ao mesmo tempo, de acordo com Guilhon (2015), acerca dos corpos acompanhados por um centro de cidadania LGBT, estes são corpos que contam e recontam sua história, que subvertem e se reivindicam, corpos específicos e com especificidades deslocam as especificações e afrouxam as amarras, corpos desejados e cobiçados, corpos engravidados com inseminação caseira, corpos transformados e em transformação, corpos pintados, perfumados e performáticos, corpos abençoados e amaldiçoados, corpos que apenas desejam ser corpos, com seus significados, visibilidades, potencialidades e multiplicidades. Da mesma forma, a multiplicidade de modos de ser das famílias e o modo como a Justiça e a Psicologia se relacionam com elas, especialmente, as que fogem aos padrões impostos, pode ser pensada a partir do poder, enquanto um feixe de relações, cujos fios e linhas ao serem seguidos, apresentam-nos algumas pistas para lançar luz aos processos - afetivos, subjetivos e legais - que envolvem as famílias transhomoparentais.

Ao tomarmos esse texto enquanto uma escrita cartográfica, fica mais evidente a possibilidade de acompanhar o modo como distintos processos ocorrem, de acordo com Regina Benevides de Barros (2013, p.234), numa cartografia "o que se faz é acompanhar as linhas que se traçam, marcar os pontos de ruptura e de enrijecimento, analisar os cruzamentos dessas linhas diversas que funcionam ao mesmo tempo". Assim, a partir do caso-disparador, se pensarmos em termos de linhas arborescentes e rizomáticas, podemos recuperar a Deleuze e Parnet, quando apontam que "indivíduos ou grupos, somos feitos de linhas, e essas linhas são de muito diversa natureza" (2004, p. 151), linhas que podem ser entendidas a partir de três aspectos: o primeiro aspecto de uma segmentaridade dura ou bem determinado, outro mais flexível e um terceiro mais abstrato.

Como exemplos dos segmentos mais endurecidos, podemos tomar a família, a profissão e o reconhecimento jurídico, especialmente quando se passa de um ao outro de modo que nada mais é como se era antes, e este novo lugar é tão segmentado, marcado e duro quanto o anterior. Segundo os autores, os segmentos que constituem estas linhas mais duras dependem de máquinas binárias de classes sociais, de sexos, gêneros, idades, criança-adulto, branco-negros, de classes, de subjetivações que ocorrem tanto em nós quanto fora de nós, produzindo constantemente escolhas binárias (Deleuze \& Parnet, 2004, p. 155-156).

A segunda linha (Deleuze \& Parnet, 2004, p. 151) se refere à possibilidade de uma segmentaridade mais flexiva, o segundo aspecto destas linhas, pois que "traçam pequenas modificações, fazem desvios, esboçam quedas ou impulsos"; contudo, apesar de flexíveis, não são menos precisas, 
considerando que dirigem processos irreversíveis.

Simples e abstrata, mais complicada e mais sinuosa, assim se apresenta a terceira linha, sendo "como se algo nos levasse, através de nossos segmentos, mas também através dos nossos limiares, para um destino desconhecido, não previsível, não preexistente" (Deleuze \& Parnet, 2004, p. 152), traçando, neste sentido, "uma outra linha no meio da linha segmentária, no meio dos segmentos, que os arrastará segundo velocidades e lentidões variáveis num movimento de fuga ou de fluxos" (Deleuze \& Parnet, 2004, p. 158).

\section{Considerações Finais}

Na perspectiva de acompanhar, a partir do caso-disparador apresentado, as diferentes linhas que foram se apresentando à trajetória desse núcleo (descentrado) familiar, que foi passando por diferentes transformações. Da gestação em decorrência do estupro de uma adolescente, à chegada de outra filha dentro de um relacionamento estável heterossexual, à construção de uma sexualidade lésbica por $\mathrm{M}$. e posteriormente à afirmação do gênero masculino, aos trâmites legais para retificação de nome e gênero no registro civil e o exercício da função paterna. Desta forma, podemos pensar, no campo das micro afetações, sobre os desafios que se apresentam e nos convocam, enquanto profissionais, para " a construir intervenções que disparem novos processos de subjetivação e que assegurem vivências outras, às vezes para além daquelas pautadas pelo binarismo de gênero e pela heteronormatividade, promovendo saúde, qualidade de vida e cidadania" (Guilhon, 2015, p.27).

Assim, o nosso caso-disparador, que irrompe e grita a partir de muitos casos, incita o pensamento enquanto estratégia que possibilita que compreendamos as relações de força que constituem ações e experiências familiares, que experimentam possibilidades e impossibilidades tanto no cotidiano molecular no plano das sensações, dos processos - quanto na engrenagem jurídica molar - das diferenças sociais mais amplas, da política, da constituição das grandes identidades- (Guattari \& Rolnik, 2011), planos que se entrecruzam, se complementam, se contrapõem, se tensionam.

Cabe apontar que este caso não se apresenta enquanto representativo, mas supõe uma problematização aos modelos e relações estabelecidos. A família, como o gênero, são aqui entendidos enquanto instituiçõesdispositivos que são históricos, mutáveis e permanentemente perpassados pelas normas e suas transgressões. Faz-se um chamado a mais estudos e pesquisas desde esta perspectiva, que busquem explorar as experimentações de vida, que considerem as relações de poder que se instauram nas famílias e entre as famílias e a sociedade. Deste modo, o exercício democrático é fundamental no sentido mais amplo, na autonomia e autodeterminação de sujeitos e coletivos nas diversas dimensões das suas existências, clamando por um aprofundamento na produção de conhecimento que advogue pela sua resistência.

Nesse sentido, chamamos a atenção para a relevância do papel de uma Psicologia crítica e mais engajada política e socialmente com a emancipação das minorias de direitos. No campo em que famílias e Justiça se encontram, profissionais da Psicologia - na pesquisa e/ou na atuação direta junto aos usuários e usuárias - comprometidas/os com o cuidado - enquanto postura ético-política de expansão de territórios existenciais - podem criar a capacidade de desnaturalizar práticas de tutelagem, além de afirmar a vida a partir de intervenções que produzam novos mundos, juntamente com a possibilidade de habitá-los com maior potência e autonomia 


\section{Referências}

Azerêdo, S. (2010). Encrenca de gênero nas teorizações em psicologia. Revista Estudos Feministas, 18(1), 175-188. doi:10.1590/S0104-026X2010000100011

Barros, R. B. (2013). Grupo: a afirmação de um simulacro. (3. ed., Coleção Cartografias). Porto Alegre: Sulina/Ed. UFRG.

Brito, L. M. T., \& Ayres, L. S. M. (2004). Destituição do Poder Familiar e Dúvidas Sobre a Filiação. Revista Brasileira de Direito de Família, 6(26), 129-143.

Butler, J. (1998). Actos performativos y constitución del gênero: un ensayo sobre fenomenología y teoría feminista. Debate Feminista, 18, 296-314.

Butler, J. (2013). Corpos que pesam: sobre os limites discursivos do "sexo". In G. L. Louro. Corpo Educado: pedagogias da sexualidade (3 ed.). Belo Horizonte, $\mathrm{BH}$ : Autêntica.

Corrêa, M. (2012). Gênero, genealogias e novas famílias. Mediações, 17(1), 191-215. doi: 10.5433/2176-6665.2012v17n1p191

Costa, R. G. (2002). Reprodução e gênero: paternidades, masculinidades e teorias da concepção. Revista Estudos Feministas, 10(2), 339-356. doi: 10.1590/S0104-026X2002000200005

De Garay Hernández, J. (2013). Filhas de famílias homoparentais: processos, confrontos e pluralidades (Dissertação de Mestrado). Instituto de Psicologia, Universidade do Estado do Rio de Janeiro, RJ, Brasil.

Deleuze, G., \& Guattari, F. (1995). Mil platôs. Capitalismo e Esquizofrenia 2 (vol.1, A. L. Oliveira, A. Guerra Neto, \& C. P. Costa, Trad.). São Paulo, SP: Ed 34.

Deleuze, G., \& Parnet, C. (2004). Diálogos (J. G. Cunha, Trad.). Lisboa: Ed. Relógio D’Água.

Fine, A. (2001). Vers une reconnaissance de la pluriparentalité?. Esprit (1940-), 273(3/4), 40-52. Recuperado de www.jstor.org/stable/24278951

Fonseca, C. (2009). Aventuras familiares: do acolhimento à adoção. In C. Fonseca, P.
Schuch (Orgs.), Políticas de proteção à infância: um olhar antropológico (pp. 273294). Porto Alegre: UFRGS

Fonseca, C. (2008). Homoparentalidade: novas luzes sobre o parentesco. Revista Estudos Feministas, 16(3), 769-783. doi: 10.1590/S0104-026X2008000300003

Foucault, M. (1979). Microfísica do Poder (23 ed., R. Macahdo, Org.). Rio de Janeiro, RJ: Edições Graal.

Guattari, F., \& Rolnik, S. (2011). Micropolítica: cartografias do desejo (11 ed). Petrópolis, RJ: Vozes.

Guilhon, F. L. (2015). Pirateando afetos e produzindo práticas: viagens pelo Centro de Cidadania LGBT (Dissertação de Mestrado). Instituto de Psicologia, Universidade do Estado do Rio de Janeiro, Rio de Janeiro.

Haraway, D. (2004). "Gênero" para um dicionário marxista: a política sexual de uma palavra. Cadernos Pagu, (22), 201246. doi: 10.1590/S010483332004000100009

Kastrup, V. (2012). Inventar. In T. Fonseca, M. Nascimento, \& C. Maraschin (Orgs.), Pesquisar na diferença: um abecedário (pp. 237-240). Porto Alegre: Sulina.

Louro, G. L. (2013). Pedagogias da sexualidade. In G. L. Louro. Corpo Educado: pedagogias da sexualidade (3 ed.). Belo Horizonte, BH: Autêntica.

Mello, L. (2005). Novas famílias: conjugalidade homossexual no Brasil contemporâneo. Rio de Janeiro: Garamond.

Moraes, M. (2014). O sistema judicial brasileiro e a definição do melhor interesse da criança. Revista Estudos de Sociologia, 19(36), 21-39. Recuperado de https://periodicos.fclar.unesp.br/estudos/arti cle/view/5931

Núcleo de Direitos Humanos e Cidadania LGBT (NUH-UFMG) Departamento de Antropologia e Arqueologia (DAAUFMG). (2015). Projeto transexualidades e saúde pública no Brasil: entre a invisibilidade e a demanda por políticas públicas para homens trans. UFMG. 
Recuperado de

http://www.nuhufmg.com.br/homens-transrelatorio2.pdf

Peres, M, Soares, S., \& Dias, M. (2018).

Dossiê sobre lesbocídio no Brasil: de 2014

até 2017. Rio de Janeiro: Livros Ilimitados.

Recuperado de

https://dossies.agenciapatriciagalvao.org.br/

fontes-e-pesquisas/wp-

content/uploads/sites/3/2018/04/Dossi\%C3

\%AA-sobre-lesboc\%C3\%ADdio-no-

Brasil.pdf

Pontes, M. F., Feres-Carneiro, T., \&

Magalhães, A. S. (2017).

Homoparentalidade feminina: laço

biológico e laço afetivo na dinâmica

familiar. Psicologia USP, 28(2), 276-

286. doi: $10.1590 / 0103-656420150175$
Rolnik, S. (1993). Pensamento, corpo e devir: uma perspectiva ético/estético/política no trabalho acadêmico. Cadernos de subjetividade, 1(2), 241251.doi: 10.2354/cs.v1i2.38134

Saffioti, H. I. B. (2004). Gênero, patriarcado, violência. São Paulo: Editora Fundação Perseu Abramo.

Tarnovski, F. (2013). Parentalidade e gênero em famílias homoparentais francesas. Cadernos Pagu, (40), 67-93. doi: 10.1590/S0104-83332013000100002

Vianna, A.R.B. (2006). Quem deve guardar as crianças? In A. C. S. Lima (Org), Gestar e Gerir: estudos para uma antropologia da administração pública no Brasil. (p. 271312). Rio de Janeiro, RJ: Relume Dumará.

\section{Dados sobre os autores:}

- Jimena de Garay Hernández: Doutora em Psicologia Social pela UERJ, professora adjunta no Instituto de Psicologia da Universidade do Estado do Rio de Janeiro.

- Roberta Gomes Nunes: Mestre em Psicologia social pela UERJ, psicóloga do Tribunal de Justiça do Estado do Rio de Janeiro e instrutora da Escola de Administração Judiciária.

- Flávio Lopes Guilhon: Doutorando no Programa de Pós-Graduação em Psicologia da Universidade Federal Fluminense. Atua na Secretaria Municipal de Saúde da Prefeitura Municipal de Rio das Ostras no Programa Municipal de Saúde Mental (SAÚDE) e na UNIGRANRIO, como professor colaborador. 